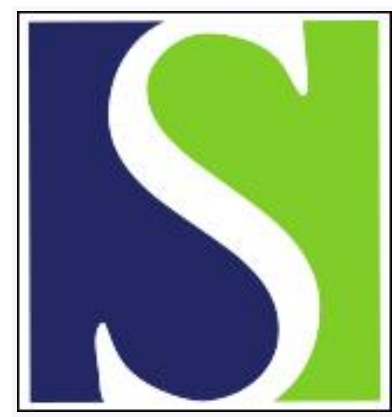

Scand J Work Environ Health 2019;45(3):298-307

https://doi.org/10.5271/sjweh.3798

Published online: 11 Jan 2019, Issue date: 01 May 2019

Neurocognitive function in relation to blood lead among young men prior to chronic occupational exposure

by Yu C-G, Yang W-Y, Saenen N, Wei F-F, Zhang Z-Y, Mujaj B, Thijs L, Feng Y-M, Nawrot TS, Staessen JA

We assessed the cross-sectional associations of blood lead with neurocognitive performance, captured by the Stroop and digit symbol tests, in 339 young American men prior to occupational exposure. We failed to demonstrate any significant association, suggesting that at contemporary environmental exposure levels, lead cannot be an important determinant of cognitive performance in men at an average age of 28 years.

Affiliation: Department of Cardiovascular Diseases, University of Leuven, Campus Sint Rafaël, Kapucijnenvoer 35, Box 7001, BE-3000 Leuven, Belgium. jan.staessen@med.kuleuven.be

The following article refers to this text: 2021;47(3):233-243

Key terms: blood lead; chronic occupational exposure; digit symbol test; environmental exposure; exposure; lead; men; neurocognitive function; occupational exposure; Stroop test

This article in PubMed: www.ncbi.nlm.nih.gov/pubmed/30631878 


\title{
Neurocognitive function in relation to blood lead among young men prior to chronic occupational exposure
}

\author{
by Cai-Guo Yu, MD, 1,2 Wen-Yi Yang, MD, 1,3 Nelly Saenen, MD, ${ }^{4}$ Fang-Fei Wei, MD, ${ }^{1}$ Zhen-Yu Zhang, MD, PhD, 1,5 Blerim Mujaj, \\ MD, ${ }^{1}$ Lutgarde Thijs, MSc, ${ }^{1}$ Ying-Mei Feng, PhD, ${ }^{2}$ Tim S Nawrot PhD, ${ }^{4}$ Jan A Staessen, MD, PhD ${ }^{1,6}$
}

\begin{abstract}
Yu C-G, Yang W-Y, Saenen N, Wei F-F, Zhang Z-Y, Mujaj B, Thijs L, Feng Y-M, Nawrot TS, Staessen JA. Neurocognitive function in relation to blood lead among young men prior to chronic occupational exposure. Scand J Work Environ Health. 2019;45(3):298-307. doi:10.5271/sjweh.3798
\end{abstract}

\begin{abstract}
Objectives Higher than contemporary exposure levels and advanced age of study participants have limited the interpretation of previous studies relating neurocognitive function to lead exposure. We reassessed this association in young American men prior to chronic occupational exposure at lead recycling plants, using baseline measurements of the Study for Promotion of Health in Recycling Lead (NCT02243904).
\end{abstract}

\begin{abstract}
Methods We administered the Stroop test (ST) and the digit-symbol test (DST) to 339 men (mean age, 28.6 years; participation rate $82.7 \%$ ). Whole blood lead (BL) was determined by inductively coupled plasma mass spectrometry and related ST and DST test results using multivariable-adjusted regression.

Results Average values were $4.26 \mu \mathrm{g} / \mathrm{dL}$ for BL, $1624 \mathrm{~ms}$ and $1474 \mathrm{~ms}$ for mean reaction time in incongruent and congruent ST trials, and $109 \mathrm{sec}$ for mean total latency in DST. The number of participants with fully correct answers amounted to $281(82.9 \%)$ and 334 (98.5\%) in incongruent and congruent ST trials, respectively, and to 198 (58.4\%) in the DST. In multivariable-adjusted analyses, there was no association between cognitive performance and BL except for a weak but opposite association in DST; for a 10-fold BL increment, mean total latency was $5.4 \%(95 \%$ confidence interval, $-0.4-11.5 \% ; \mathrm{P}=0.066)$ higher, whereas the error score was $42 \%$ $(-10-69 \% ; \mathrm{P}=0.096)$ lower. To exclude an effect of the cumulative lead dose, sensitivity analyses restricted to workers $<40,35$ and 30 years were confirmatory.
\end{abstract}

Conclusions At the exposure levels in our current study, we failed to demonstrate a consistent inverse association of BL with neurocognitive performance in young American men.

Key terms digit symbol test; environmental exposure; Stroop test.

There is abundant literature relating neurocognitive function to lead exposure in studies of the general populations $(1-7)$ or workers $(8-11)$ with a cross-sectional $(1-3,5,6,8)$, case-control $(9,11)$ or longitudinal $(4,7$, 10) design. A review published in 2007 concluded there is sufficient evidence to support an association in adults between decline in cognitive function and the internal lead dose assessed from the concentration in bone or blood (12). Bone lead is an index of the cumulative lifetime exposure and has a long half-life (20-25 years), in particular when deposited in the cortex of the tibia. Blood lead reflects recent exposure and recirculation of lead from bone tissue and has a much shorter halflife (1-2 months) (13). Associations of neurocognitive function with the cumulative lead dose (bone lead) in workers with past occupational exposure were stronger and more consistent than associations with blood lead (12). Conversely, studies of currently exposed workers

1 Studies Coordinating Centre, Research Unit Hypertension and Cardiovascular Epidemiology, KU Leuven Department of Cardiovascular Sciences, University of Leuven, Leuven, Belgium.

2 Department of Endocrinology, Beijing Lu He Hospital and Key Laboratory of Diabetes Prevention and Research, Capital Medical University, Beijing, China.

3 Department of Cardiology, Shanghai General Hospital, Shanghai Jiao Tong University School of Medicine, Shanghai, China.

4 Centre for Environmental Sciences, Hasselt University, Diepenbeek, Belgium.

5 Institut Universitaire de Médicine Sociale et Préventive, University of Lausanne, Lausanne, Switzerland.

6 Cardiovascular Research Institute Maastricht (CARIM), Maastricht University, Maastricht, The Netherlands.

Correspondence to: Jan A Staessen, Studies Coordinating Centre, Research Unit Hypertension and Cardiovascular Epidemiology, KU Leuven Department of Cardiovascular Diseases, University of Leuven, Campus Sint Rafaël, Kapucijnenvoer 35, Box 7001, BE-3000 Leuven, Belgium. [E-mail: jan.staessen@med.kuleuven.be] 
generally found associations that were more apparent with blood lead levels (12).

Among adults, mean blood lead levels decreased from $13.1 \mu \mathrm{g} / \mathrm{dL}$ in the National Health and Nutrition Examination Survey II (NHANES II; 1976-1980) (14, $15)$ to 1.2 to $2.76 \mu \mathrm{g} / \mathrm{dL}$ in NHANES III (1988-1994) (16) and to $1.64 \mu \mathrm{g} / \mathrm{dL}$ in NHANES IV (1999-2002) (16). In previous publications, the blood lead concentration averaged from $30.8(9)$ to $32.0(8) \mu \mathrm{g} / \mathrm{dL}$ in workers and from 2.5 (6) to $5.5(1) \mu \mathrm{g} / \mathrm{dL}$ in studies of the general population. One factor limiting the interpretation of previous studies is the advanced age of the participants. Mean age in the worker studies ranged from 39.5 (9) to 41.4 (10) years and in the population studies from 59.4 (3) to 72.0 (6) years. Blood lead level is a measure of the current biologically active lead burden, but - in older people - the acute effects of a high recent lead exposure may be masked by the chronic effects of the cumulative exposure $(12,17)$. The cumulative lead body burden increases with advancing age (13). We therefore reassessed the association of neurocognitive function with blood lead, using the baseline measurements (20152017) collected in the ongoing Study for Promotion of Health in Recycling Lead (SPHERL; NCT02243904). Study participants were young men (mean age, 28.6 years), examined prior to chronic occupational exposure at lead recycling plants in the United States (18).

\section{Methods}

\section{Participants}

SPHERL is a longitudinal study of newly hired lead workers at battery manufacturing and lead recycling plants in the United States (18), which complies with the Helsinki declaration for investigations in humans (19). The Ethics Committee of the University Hospitals Leuven (Belgium) approved the study protocol. Of 556 men invited from 1 May 2015 until 19 September 2017, 460 gave written informed consent (participation rate, $82.7 \%$ ). Of those, 386 underwent neurocognitive testing and had their blood lead levels measured. We excluded 47 workers from the current analysis due to previous occupational exposure to lead $(\mathrm{N}=41)$ or because outcome measures $(\mathrm{N}=3)$ or covariables $(\mathrm{N}=3)$ were $>3$ standard deviations (SD) above the population mean. Thus, the number of workers statistically analyzed totaled 339 .

\section{Data collection}

Clinical measurements. Blood pressure was the average of five consecutive auscultatory readings obtained with a standard mercury sphygmomanometer after the workers had rested for $\geq 5$ minutes in the sitting position. Mean arterial pressure was diastolic pressure plus one-third of the difference between systolic and diastolic pressure. Hypertension was a blood pressure of $\geq 140 \mathrm{~mm} \mathrm{Hg}$ systolic or $\geq 90 \mathrm{~mm} \mathrm{Hg}$ diastolic or use of antihypertensive drugs. Body mass index (BMI) was body weight $(\mathrm{kg})$ divided by height squared $\left(\mathrm{m}^{2}\right)$. The umbilicus and greater trochanter were the landmarks for measuring waist and hip circumference, respectively. Study nurses administered validated $(20,21)$ questionnaires, inquiring about each worker's medical history, occupations, exposure to heavy metals, smoking and drinking habits, intake of medications and lifestyle.

Biochemical measurements. Venous blood samples were obtained after 8-12 hours of fasting. Blood lead levels were determined on whole blood by inductively coupled plasma mass spectrometry at an analytical laboratory certified for blood lead analysis in compliance with the provisions of the OSHA Lead Standard, 29CFR 1910.1025 (Occupational Safety and Health Administration [www. osha.gov]). Prior to analysis, the specimens were digested with nitric acid and spiked with an iridium internal standard. The detection limit was $0.5 \mu \mathrm{g} / \mathrm{dL}$. The accuracy of the lead tests was verified by use of proficiency samples purchased from the College of American Pathologists (CAP) and the Pennsylvania Department of Blood Lead Programs (22). Proficiency testing was performed in six separate trial runs, including in total 30 test samples annually. All survey materials were handled in the same manner as the study samples and processed with the normal workflow utilizing the same repeat/dilution protocols and calibration and quality control frequency (23). Compliance with Clinical Laboratory Improvement Amendments (CLIA), CAP and New York State accreditation and regulatory requirements was verified routinely with test level review of the laboratory services by external auditors. Calibrators with certified accuracy (National Institute of Standards and Technology [www.nist.gov]) were included in each batch of study samples and spanned the range of the analytical measurement range. Accuracy was evaluated on Westgard Rules (24) and defined within the total allowable error established with review of the CAP, Centers for Disease Control and Prevention, CLIA 88 (25), and OSHA guidelines. Accuracy, defined as the deviation from known lead standards ran along with the study samples, was within $10 \%$ (23). The bias determined according to the Bland \& Altman approach (26) in 30 spilt blood samples with blood lead concentrations (average in duplicate samples) ranging from $0.70-27.9 \mu \mathrm{g} / \mathrm{dL}$, was $0.08 \mu \mathrm{g} / \mathrm{dL}[95 \%$ confidence interval (CI) $-0.01-0.18$, $\mathrm{P}=0.078$, figure 1]. The repeatability coefficient, defined as twice the SD of the signed differences between duplicate measurements (26), was 0.52. Expressed as a percentage of the mean blood lead concentration or as a 


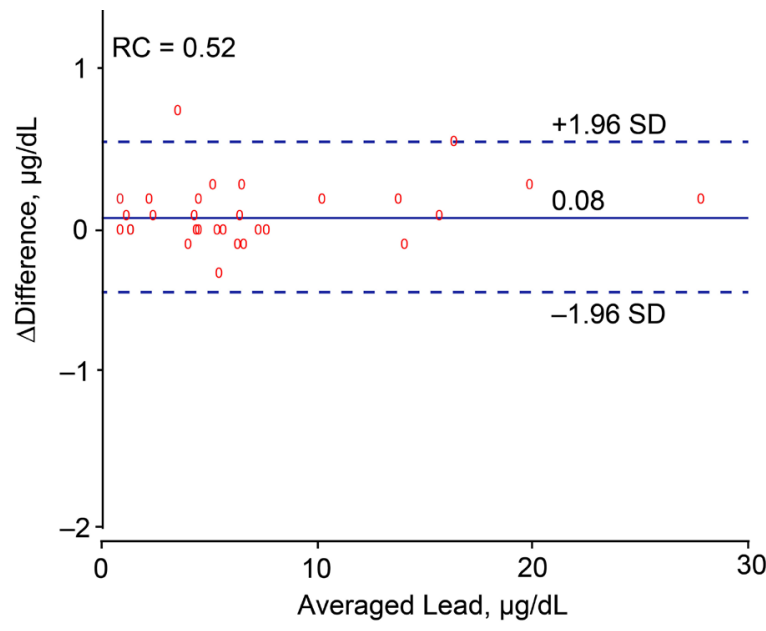

Figure 1. Bland-Altman plot for duplicate blood lead measurements in 30 workers. The difference between both measurements was plotted against the average of both measurements. The difference was calculated by subtracting the lead concentration in the split sample from the lead concentration level used for the current analysis. The bias was $0.08 \mu \mathrm{g} / \mathrm{dL}(P=0.078)$. The reproducibility coefficient $(\mathrm{RC})$ is twice the standard deviation (SD) of the signed differences between duplicate measurements.

percentage of near maximal variation in blood lead (four times the SD of the logarithmically transformed distribution), the repeatability coefficient was $6.7 \%$ and $1.9 \%$, respectively. Lower values indicate better repeatability. Serum total and high-density lipoprotein (HDL) cholesterol and blood glucose were measured by automated enzymatic methods and serum insulin by ELISA. Over three evaluations, the laboratory obtained a proficiency score of $100 \%$ for blood lead, $100 \%$ for routine biochemistry, and $98 \%$ for serum insulin.

Neurocognitive function tests The neurocognitive examination took place in a quiet room. We administered a computer version of the Stroop test (ST) (Xavier Educational Software Ltd, Bangor, Wales, UK) and digitsymbol test, using a laptop with touch screen.

Stroop test. In the ST (selective attention domain), workers saw the printed name of a color and four buttons displayed in yellow, red, blue and green on a computer screen. In congruent trials, the name of the color is printed in the matching color (eg, "yellow" is printed in yellow). In incongruent trials, the name of the color is printed in a different color (eg, "yellow" is printed in red). The task consists of touching the button with the color matching the printed name of the color as fast and accurately as possible, ignoring the color of the printed color name. The ST consisted of 4 congruent and 12 incongruent trials. Before the test, participants completed a few practice trials. The mean reaction time is the average time that passed between the appearance of the color name and touching the correct button in congruent and incongruent trials. Interference effect and score were respectively calculated as the absolute difference between mean reaction time of congruent and incongruent trials and as the difference of the proportion of the correct answers in congruent trials minus the proportion of correct answers in incongruent trials.

The digit-symbol test. The digit-symbol test (DST) measures the speed of visual scanning and processing of visual information (27). A row of 9 symbols paired vertically with 9 digits is displayed at the top of the computer screen. The same symbols are also presented at the bottom of the screen but in a different order. During the test, 27 digits appear one after one in the center of the screen. The task is to touch as fast as possible the symbol at the bottom of the screen that is paired with a displayed digit. The subject has to make the correct response before a new digit is presented.

\section{Statistical analysis}

Database management and statistical analysis were done using SAS 9.4 software (SAS Institute, Cary, NC, USA). The flow and quality control of the data are described in the published protocol (18). Departure from normality was evaluated using Shapiro-Wilk's statistic. Skewness and kurtosis were computed as the third and fourth moments of the mean divided by the cube of the SD. We applied a logarithmic transformation (base 10) to normalize the distributions of mean reaction time and interference effect (ST), total correct time (DST), and blood lead and serum insulin. The central tendency (spread) of normally distributed variables was represented by the arithmetic (SD) or geometric (interquartile range) mean. To compare means and proportions, we applied a $\mathrm{t}$-statistic or ANOVA, as appropriate, and the chi-square statistic or Fisher exact test, respectively. Significance was a 2 -tailed $\alpha$-level of $\leq 0.05$.

In exploratory analyses, we assessed ST and DST measurements across thirds (tertiles) of the blood lead distribution. P-values for trend were computed by the chisquare statistic for categorical variables or by regressing continuously distributed variables on a design variable identifying the thirds of the blood lead distribution with as values 1,2 or 3 . Next, we computed the multivariableadjusted associations of the neurocognitive variables with blood lead, using linear or logistic regression. We identified potential covariables by stepwise regression analysis with the P-value for variables to enter and stay in the models set at 0.15 . The covariables considered were ethnicity, age, body mass index, waist-to-hip ratio, mean arterial pressure, heart rate, current smoking and drinking, 
educational attainment, history of diabetes, drug treatment for hypertension, serum insulin levels and the total-toHDL cholesterol ratio. For each outcome, we presented two models, first adjusting for covariables consistently associated with more than two outcome measures and next additionally adjusting for covariables, which were only associated with one or two outcomes. Association sizes, given for a 10 -fold increase in blood lead, were presented as a percentage difference in logarithmically transformed continuously distributed outcome measures or as an odds ratio (OR) for categorical outcomes.

\section{Results}

\section{Characteristics of participants}

The 339 newly hired workers included 160 whites (47.2\%), 154 Hispanics (45.4\%), 15 blacks (4.4\%), 3 Asians ( $0.9 \%$ ), and 7 workers of mixed ethnicity (2.1\%). Prevalence amounted to $100(29.5 \%)$ for current smoking, $45(13.3 \%)$ for past smoking, 141 (41.6\%) for alcohol consumption, $35(10.3 \%)$ and $23(6.8 \%)$ for hypertension and treated hypertension, respectively, and $7(2.1 \%)$ for diabetes mellitus. Educational attainment was at the level of middle school or less in $12(3.5 \%)$ participants, high school in $271(80.0 \%)$, and college or university in $56(16.5 \%)$. Among all workers, average values were 28.6 (SD 10.2) years for age [interquartile range (IR) 21.4-31.6 years], 120.6 (SD 10.0) $\mathrm{mm} \mathrm{Hg}$ and 80.6 (SD 8.6) $\mathrm{mm} \mathrm{Hg}$ for systolic and diastolic blood pressure, respectively, and 28.5 (SD 6.0) $\mathrm{kg} / \mathrm{m}^{2}$ for BMI. The geometric mean blood lead concentration at the pre-employment physical examination was 2.47 (IR 2.00-3.00) $\mu \mathrm{g} / \mathrm{dL}$. The first assessment of blood lead for the current study, done simultaneously with the neurocognitive assessment, was performed 21 (IR 10-31) days after workers had started employment. At that time point, the geometric mean blood lead concentration was 4.26 (IR 2.50-8.30) $\mu \mathrm{g} / \mathrm{dL}$ (figure 2).

Table 1 lists the characteristics of the workers by thirds of the blood lead distribution. Across increasing lead categories, BMI, the waist-to-hip ratio, total cholesterol, and the total-to HDL cholesterol ratio decreased ( $\mathrm{P}$ for trend $\leq 0.022)$, but HDL increased $(\mathrm{P}=0.038)$.

\section{Neurocognitive test results}

Among all participants, the mean ST reaction time was 1624 (IR 1278-1990) ms for incongruent trials and 1474 (IR 1162-1767) ms for congruent trials. The geometric mean interference effect was 166 (IR 94-375) ms. The number of participants with fully correct answers in incongruent trials was $281(82.9 \%)$ and 334 (98.5\%) in

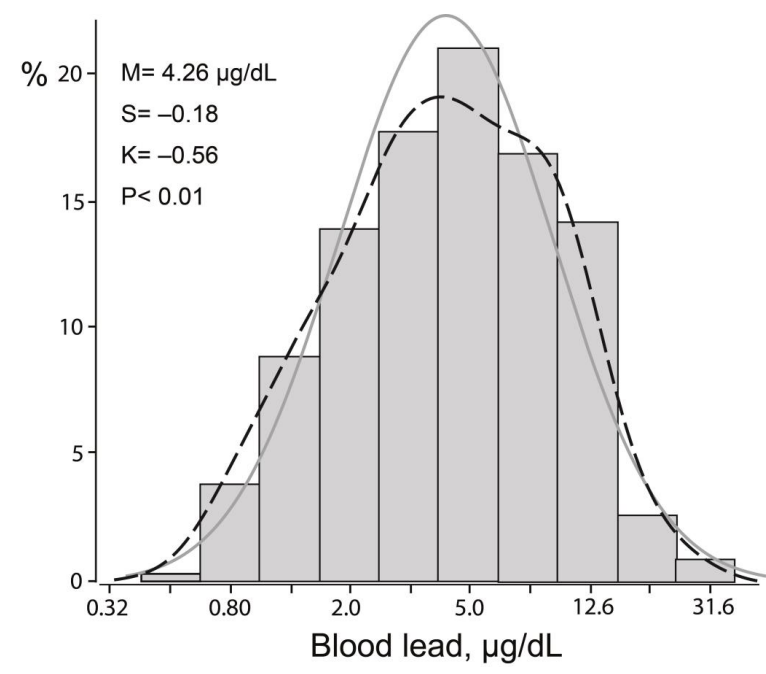

Figure 2. Distributions of logarithmically transformed blood lead. M, S and Kindicate the mean and the coefficients of skewness and kurtosis. The solid and dotted lines represent the normal and kernel density distributions. The P-value is for departure of the actually observed distribution from normality according to Shapiro-Wilk's statistic.

congruent trials. In the DST, the mean total latency averaged 109 (IR 96-121) seconds. Among all participants, 198 (58.4\%) completed the DST completely error free, and $91(26.8 \%)$ and $50(14.7 \%)$ with 1 or $\geq 2$ errors, respectively.

Table 2 lists the performance of the workers in the neurocognitive tests by thirds of the blood lead distribution. With the exception of a marginally worse performance in congruent trials of the ST in the middle third of the blood lead distribution ( $\mathrm{P}=\sim 0.07$; table 2$)$, the unadjusted analyses did not reveal any significant trend across increasing categories of blood lead (P for trend $\geq 0.15$ ).

\section{Linear regression analysis}

We performed linear regression analysis relating the continuously distributed neurocognitive outcomes to blood lead, first unadjusted, next adjusted for age, current smoking and drinking, and the total-to-HDL cholesterol ratio, and finally fully adjusted also accounting for the ethnicity, waist-to-hip ratio, heart rate, educational attainment and serum insulin. Irrespective of adjustment, none of these associations reached statistical significance $(P \geq 0.27)$, with the exception of a weak positive association of the mean total latency in the DST in adjusted and fully adjusted models $(\mathrm{P} \leq 0.097$; figure 3$)$.

To exclude a background effect of the cumulative lead dose, in sensitivity analyses, we computed the fullyadjusted slope of the mean total latency on blood lead in participants younger than 40 years $(\mathrm{N}=288), 35$ years 
Table 1. Characteristics of workers by thirds of the blood lead distribution. Average values are arithmetic [standard deviation (SD)] or geometric means [interquartile range (IR)]. Hypertension was a blood pressure of $\geq 140 \mathrm{~mm} \mathrm{Hg}$ systolic, or $\geq 90 \mathrm{~mm} \mathrm{Hg}$ diastolic, or use of antihypertensive drugs. Mean arterial pressure was diastolic pressure plus one-third of the difference between systolic and diastolic pressure. [HDL=high-density lipoprotein].

\begin{tabular}{|c|c|c|c|c|c|c|c|c|c|c|c|c|c|}
\hline \multirow[t]{2}{*}{ Characteristic } & \multicolumn{4}{|c|}{$<3.0 \mu \mathrm{g} / \mathrm{dL}(\mathrm{N}=112)$} & \multicolumn{4}{|c|}{$3.0-6.5 \mu \mathrm{g} / \mathrm{dL}(\mathrm{N}=112)$} & \multicolumn{4}{|c|}{$\geq 6.5 \mu \mathrm{g} / \mathrm{dL}(\mathrm{N}=115)$} & \multirow{2}{*}{$\begin{array}{l}\text { P for linear } \\
\text { trend }\end{array}$} \\
\hline & $\mathrm{N}$ & $\%$ & Mean & $\mathrm{SD} / \mathrm{IR}$ & $\mathrm{N}$ & $\%$ & Mean & $\mathrm{SD} / \mathrm{IR}$ & $\mathrm{N}$ & $\%$ & Mean & $\mathrm{SD} / \mathrm{IR}$ & \\
\hline \multicolumn{14}{|l|}{ Smoking } \\
\hline Current & 30 & 26.8 & & & 33 & 29.5 & & & 37 & 32.2 & & & 0.67 \\
\hline Past & 13 & 11.6 & & & 20 & 17.8 & & & 12 & 10.4 & & & 0.74 \\
\hline Alcohol consumption & 47 & 42.0 & & & 54 & 48.2 & & & 40 & 34.8 & & & 0.12 \\
\hline \multicolumn{14}{|l|}{ Education } \\
\hline Less than high school & 4 & 3.6 & & & 2 & 1.8 & & & 6 & 5.2 & & & \\
\hline High school or equal & 85 & 75.9 & & & 93 & 83.0 & & & 93 & 80.9 & & & 0.41 \\
\hline College or university & 23 & 20.5 & & & 17 & 15.2 & & & 16 & 13.9 & & & \\
\hline Hypertension & 10 & 8.9 & & & 17 & 15.2 & & & 8 & 7.0 & & & 0.11 \\
\hline Treated hypertension & 8 & 7.1 & & & 12 & 10.7 & & & $3^{a}$ & 2.6 & & & 0.052 \\
\hline Diabetes mellitus & 1 & 0.9 & & & 4 & 3.6 & & & 2 & 1.7 & & & 0.35 \\
\hline Age (years) & & & 28.9 & 9.7 & & & 30.7 & 12.0 & & & $26.3^{b}$ & 8.3 & 0.054 \\
\hline Body mass index $\left(\mathrm{kg} / \mathrm{m}^{2}\right)$ & & & 30.0 & 6.6 & & & 28.5 & 6.1 & & & 27.2 & 4.9 & 0.001 \\
\hline Waist-to-hip ratio & & & 0.97 & 0.07 & & & 0.97 & 0.07 & & & 0.95 & 0.07 & 0.011 \\
\hline Systolic pressure (mm Hg) & & & 121.1 & 9.6 & & & 121.1 & 10.4 & & & 119.6 & 9.9 & 0.28 \\
\hline Diastolic pressure (mm Hg) & & & 80.2 & 9.3 & & & 81.1 & 8.8 & & & 80.5 & 7.7 & 0.75 \\
\hline Mean arterial pressure $(\mathrm{mm} \mathrm{Hg})$ & & & 93.8 & 8.7 & & & 94.4 & 8.6 & & & 93.6 & 7.7 & 0.83 \\
\hline Heart rate (beats per minute) & & & 75.0 & 13.0 & & & 74.6 & 12.2 & & & 71.9 & 11.1 & 0.060 \\
\hline Total cholesterol (mg/dL) & & & 174.6 & 36.8 & & & 176.2 & 41.5 & & & $163.3^{c}$ & 33.6 & 0.022 \\
\hline HDL cholesterol (mg/dL) & & & 44.4 & 9.8 & & & 46.8 & 10.2 & & & 47.3 & 11.6 & 0.038 \\
\hline Total-to-HDL cholesterol ratio & & & 4.14 & 1.33 & & & 3.93 & 1.25 & & & 3.66 & 1.16 & 0.004 \\
\hline Glucose (mg/dL) & & & 93.3 & 10.9 & & & 96.6 & 15.9 & & & $92.5^{\mathrm{a}}$ & 12.1 & 0.64 \\
\hline Insulin ( $\mu \mathrm{IU} / \mathrm{mL})$ & & & 7.4 & $4.0-12.8$ & & & 6.9 & $3.7-11.8$ & & & 6.5 & $3.2-11.7$ & 0.33 \\
\hline Blood lead ( $\mu \mathrm{g} / \mathrm{dL})$ & & & 1.7 & $1.3-2.5$ & & & $4.3^{b}$ & $3.5-5.2$ & & & $10.5^{b}$ & $8.0-12.1$ & $<0.001$ \\
\hline
\end{tabular}

a Significance of the difference with the adjacent left column $P \leq 0.05$.

${ }^{b}$ Significance of the difference with the adjacent left column $P \leq 0.001$

${ }^{\mathrm{C}}$ Significance of the difference with the adjacent left column $\mathrm{P} \leq 0.01$.

Table 2. Neurocognitive function by thirds of the blood lead distribution. Average values are arithmetic [standard deviation ( \pm SD)] or geometric means [interquartile range (IR)]. [MRT= mean reaction time].

\begin{tabular}{|c|c|c|c|c|c|c|c|c|c|c|c|c|c|}
\hline \multirow[t]{2}{*}{ Characteristic } & \multicolumn{4}{|c|}{$<3.0 \mu \mathrm{g} / \mathrm{dL}(\mathrm{N}=112)$} & \multicolumn{4}{|c|}{$3.0-6.5 \mu \mathrm{g} / \mathrm{dL}(\mathrm{N}=112)$} & \multicolumn{4}{|c|}{$\geq 6.5 \mu \mathrm{g} / \mathrm{dL}(\mathrm{N}=115)$} & \multirow{2}{*}{$\begin{array}{l}\text { P for linear } \\
\text { trend }\end{array}$} \\
\hline & Mean & IR & $\mathrm{N}$ & $\%$ & Mean & IR & $\mathrm{N}$ & $\%$ & Mean & IR & $\mathrm{N}$ & $\%$ & \\
\hline \multicolumn{14}{|l|}{ Stroop test } \\
\hline MRT of incongruent trials (ms, log) & 1614 & $1240-2030$ & & & 1697 & 76-2085 & & & 1567 & 1209-1864 & & & 0.48 \\
\hline MRT of congruent trials (ms, log) & 1469 & $1162-1786$ & & & 1609 a & 49-2013 & & & $1357^{b}$ & $1064-1583$ & & & 0.067 \\
\hline \multicolumn{14}{|l|}{ Correct ratio in incongruent trials (\%) } \\
\hline 100 & & & 95 & 84.8 & & & 94 & 83.9 & & & 92 & 80.0 & 0.57 \\
\hline $90-99$ & & & 14 & 12.5 & & & 11 & 9.8 & & & 17 & 14.8 & \\
\hline$<90$ & & & 3 & 2.7 & & & 7 & 6.3 & & & 6 & 5.2 & \\
\hline \multicolumn{14}{|l|}{ Correct ratio in congruent trials (\%) } \\
\hline 100 & & & 112 & 100 & & & 108 & 96.4 & & & 114 & 99.1 & 0.069 \\
\hline$<100$ & & & 0 & 0 & & & 4 & 3.6 & & & 1 & 0.9 & \\
\hline Interference effect (ms, log) & 152 & $84-369$ & & & 183 & $98-380$ & & & $166^{c}$ & $94-367$ & & & 0.59 \\
\hline \multicolumn{14}{|l|}{ Interference score } \\
\hline$<0$ & & & 0 & 0 & & & 4 & 3.6 & & & 1 & 0.9 & 0.15 \\
\hline 0 & & & 95 & 84.8 & & & 93 & 83.0 & & & 92 & 80.0 & \\
\hline$>0$ & & & 17 & 15.2 & & & 15 & 13.4 & & & 22 & 19.1 & \\
\hline \multicolumn{14}{|l|}{ Digit symbol test } \\
\hline Mean total latency (seconds, log) & 107 & $93-102$ & & & 112 & $99-124$ & & & 108 & $97-121$ & & & 0.51 \\
\hline \multicolumn{14}{|l|}{ Number of errors } \\
\hline 0 & & & 60 & 53.6 & & & 62 & 55.4 & & & 76 & 66.1 & 0.33 \\
\hline 1 & & & 35 & 31.2 & & & 31 & 27.6 & & & 25 & 21.7 & \\
\hline$\geq 2$ & & & 17 & 15.2 & & & 19 & 17.0 & & & 14 & 12.2 & \\
\hline
\end{tabular}

a Significance of the difference with the adjacent left column $P \leq 0.05$.

${ }^{b}$ Significance of the difference with the adjacent left column $P \leq 0.01$.

c Significance of the difference with the adjacent left column $P \leq 0.001$. 
Unadjusted

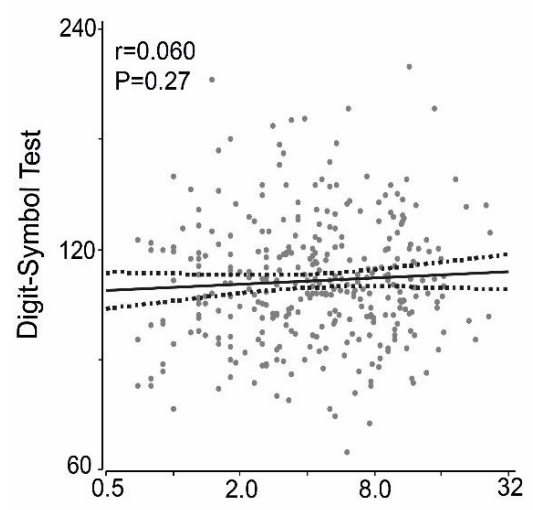

Adjusted

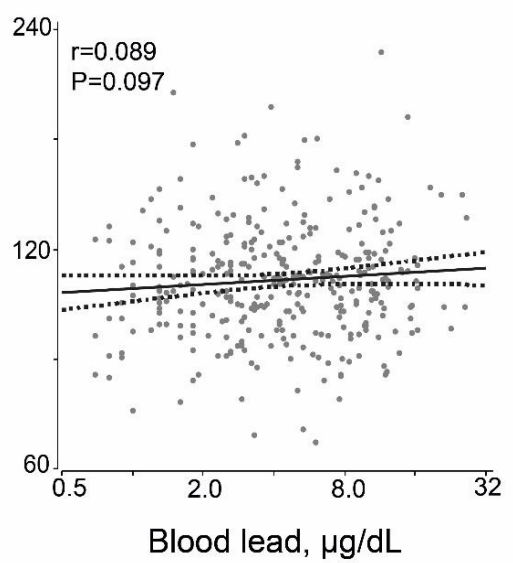

Fully adjusted

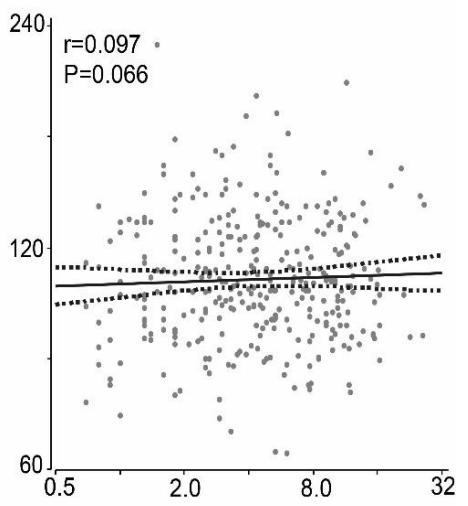

Figure 3. Correlations of mean total latency (seconds, log) with blood lead in the digit-symbol test. For each association the unadjusted, adjusted, and fully adjusted regression line with $95 \%$ confidence interval is depicted. The adjusted model accounted for age, current smoking and drinking, and the total-to-HDL cholesterol ratio and fully adjusted models additionally for ethnicity, the waist-to-hip ratio, heart rate, educational attainment and serum insulin.

Table 3. Association of neurocognitive function with blood lead. Association sizes, given for a 10 -fold increase in blood lead, were presented as a percentage difference $(\beta)$ in logarithmically transformed continuously distributed outcome measures or as an odds ratio (OR) for categorical outcomes. [MRT=mean reaction time; $\mathrm{Cl}=$ confidence interval].

\begin{tabular}{|c|c|c|c|c|c|c|c|c|c|c|c|c|}
\hline & \multicolumn{4}{|c|}{ Unadjusted } & \multicolumn{4}{|c|}{ Adjusted a } & \multicolumn{4}{|c|}{ Fully adjusted ${ }^{b}$} \\
\hline & $\beta$ & $\mathrm{OR}$ & $95 \% \mathrm{Cl}$ & P-value & $\beta$ & $\mathrm{OR}$ & $95 \% \mathrm{Cl}$ & P-value & $\beta$ & $\mathrm{OR}$ & $95 \% \mathrm{Cl}$ & P-value \\
\hline \multicolumn{13}{|l|}{ Stroop test } \\
\hline MRT of incongruent trials (\%) & 0.82 & & $-8.4-11.0$ & 0.87 & 4.0 & & $-5.4-14.3$ & 0.42 & 5.1 & & $-4.5-15.6$ & 0.30 \\
\hline MRT of congruent trials (\%) & -4.9 & & $-13.8-4.9$ & 0.31 & -2.7 & & $-11.7-7.4$ & 0.59 & -1.2 & & $-10.4-9.0$ & 0.81 \\
\hline Interference effect (\%) & 16.4 & & $-19.2-67.6$ & 0.41 & 22.1 & & $-15.6-76.7$ & 0.29 & 23.0 & & $-15.4-78.9$ & 0.28 \\
\hline \multicolumn{13}{|l|}{ Digit-symbol test } \\
\hline Mean total latency (\%) & 3.3 & & $-2.5-9.4$ & 0.27 & 4.9 & & $-0.9-10.9$ & 0.097 & 5.4 & & $-0.4-11.5$ & 0.066 \\
\hline \multicolumn{13}{|l|}{ Stroop test } \\
\hline Error score in incongruent trials & & 1.64 & $0.34-3.68$ & 0.22 & & 1.49 & $0.64-3.47$ & 0.35 & & 1.48 & $0.63-3.47$ & 0.37 \\
\hline Interference score & & 0.66 & $0.29-1.50$ & 0.32 & & 0.77 & $0.32-1.84$ & 0.56 & & 0.79 & $0.33-1.89$ & 0.59 \\
\hline \multicolumn{13}{|l|}{ Digit-symbol test } \\
\hline Error score & & 0.58 & $0.32-1.07$ & 0.082 & & 0.60 & $0.32-1.12$ & 0.109 & & 0.58 & $0.31-1.10$ & 0.096 \\
\hline
\end{tabular}

${ }^{a}$ Adjusted models accounted for age, current smoking and drinking, and total-to-HDL cholesterol ratio.

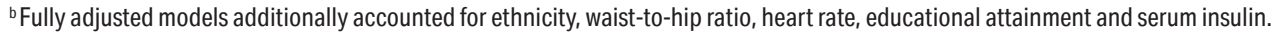

$(\mathrm{N}=277)$ and 30 years $(\mathrm{N}=237)$; the values were $6.5 \%$ (95\% CI 0.3-13.0\%; $\mathrm{P}=0.041), 6.5 \%$ (95\% CI $0.2-13.2 \%$; $\mathrm{P}=0.044)$, and $7.8 \%(95 \%$ CI $1.0-15.0 \% ; \mathrm{P}=0.023)$, respectively.

\section{Logistic regression analysis}

We ran logistic regression analyses of the categorical test results unadjusted and adjusted as before for the continuous outcomes (table 3). We did not consider the ratio of correct versus incorrect answers in congruent ST trials in view of the low frequency of incorrect tests $(\mathrm{N}=5$; table 2). Irrespective of the adjustment, there was no association of the categorical ST outcomes with blood lead. However, the DST error score $(\geq 1$ versus 0 ) was inversely albeit weakly associated with blood lead. In fully adjusted models, the OR associated with a 10 -fold increase in blood lead was $0.58(\mathrm{P}=0.096)$. In sensitivity analyses, we computed the fully adjusted OR for the DST error score in participants $<40$ years $(\mathrm{N}=288),<35$ years $(\mathrm{N}=277)$ and $<30$ years $(\mathrm{N}=237)$; the OR were $0.54(95 \%$ CI $0.27-1.08 ; \mathrm{P}=0.080), 0.56$ (95\% CI $0.28-1.14 ; \mathrm{P}=0.112)$, and 0.67 (95\% CI 0.32 $1.40 ; \mathrm{P}=0.29)$, respectively.

\section{Discussion}

Among the newly hired workers enrolled in our current study, the geometric mean blood lead concentration was $4.26 \mu \mathrm{g} / \mathrm{dL}$. We administered two neurocognitive tests. The ST provides a measure for executive functioning, selective attention, cognitive flexibility, cognitive inhibi- 
tion, and information processing speed. The DST measures visual processing speed, working memory, visuospatial processing and attention. This test appears to be sensitive to changes among people whose cognition is quite good and in whom other tests might fail to differentiate between persons with normal or just slightly impaired cognition $(28,29)$. Using these instruments, we failed to demonstrate any association between cognitive performance as measured by the ST and blood lead. However, there was a weak positive association between the mean total latency in the DST and blood lead (figure 3 ), suggesting worse performance with higher blood lead, whereas the probability of an error decreased with blood lead, suggesting better performance with higher blood lead (table 3). One possible explanation for these contradictory albeit non-significant results is that taking more time to complete the test results in a lower error rate. To exclude an effect of the cumulative lead dose, we ran sensitivity analyses evaluating the DST results among workers aged $<40,<35$ and $<30$ years, respectively. These sensitivity analyses produced confirmatory estimates for the differences in mean total latency and error score associated with a 10-fold higher blood lead.

In three studies based on NHANES that included adults aged $20-59$ years $(30,31)$ or $\geq 60$ years $(6)$, blood lead averaged 2.46-2.88 $\mu \mathrm{g} / \mathrm{dL}$. In multivariableadjusted analyses accounting for the sampling frame employed in NHANES, performance on the DST was unrelated to the blood lead concentration. In five studies in people not occupationally exposed to lead, investigators administered a comprehensive set of neurocognitive tests $(1,3-5,7)$, including the DST in the Baltimore Memory Study (BMS) (3) and measured both blood and bone lead as indexes of recent and lifetime exposure (13). Participants were community-dwelling adults (mean age, 59 years) $(3)$, older men $(68$ years) $(1,4)$ or female nurses $(61$ years) $(5,7)$. The analyses followed a cross-sectional $(1,3,5)$ or longitudinal design $(4$, 7). Sample size ranged from 141 (1) to 5662 (30). The blood lead concentration averaged $3.46 \mu \mathrm{g} / \mathrm{dL}$ in BMS (3), approximately $5.0 \mu \mathrm{g} / \mathrm{dL}$ in the Veterans Administration Study (VAS) $(1,4)$ and $2.9 \mu \mathrm{g} / \mathrm{dL}$ in the Nurses' Health Study (NHS) $(5,7)$. Analyses were adjusted for a multitude of covariables and risk factors for cognitive impairment except in the cross-sectional analysis of the VAS, which only accounted for age and education (1). In BMS, in multivariable adjusted analyses, cognitive performance in seven cognitive domains was not associated with blood lead, while the associations with bone lead lost significance with full adjustment applied (3). In VAS (4), 1089 men were enrolled, of whom 761 also had valid bone lead measurements and completed at least one of a battery of cognitive tests. Approximately 3.5 years later, $69 \%$ of the men had at least one repeat test. Cognitive testing was performed from 1993 through
2001 (4). Challenging the first VAS article, including 141 men analyzed with minimal adjustment (1), the later publication (4) concluded that on a cross-sectional basis, there was little association between cognitive function and blood or bone lead. Change in cognitive performance over time worsened as bone lead increased (4) with the most robust association on performance and reaction time scores with bone lead on visuospatial and visuomotor tests (4). The first NHS publication included 584 women in whom the investigators did a multivariable-adjusted cross-sectional analysis relating a composite score of all cognitive tests combined with the biomarkers of lead exposure (5). Results were statistically significant only for tibia lead. A 1-SD increase in tibia lead corresponded to a 0.051 -unit lower standardized summary cognitive score $(95 \%$ CI $-0.099--0.003$; $\mathrm{P}=0.04$ ), similar to the difference in cognitive scores observed between women who were three years apart in age (5). Association with patella or blood lead were not significant (5). In the longitudinal NHS analysis (7), the estimated excess annual decline in the overall cognitive test $\mathrm{z}$ score per 1-SD increment in tibia bone lead concentration was suggestive, but the CI included $0(0.024$ standard units, 95\% CI -0.053-0.004) an additional decline in function equivalent to being 0.33 years older.

Neurocognitive function involves a large number of brain areas, which have been investigated in functional neuro-imaging studies in humans performing neurobehavioral tests. Magnetic resonance imaging (MRI) studies performed during the ST identified distinct fronto-parietal networks of current trial conflict detection and conflict adaptation through cognitive control (32). Conflict adaptation was associated with increased activity in the left middle frontal gyrus and superior frontal gyrus, consistent with increased cognitive control, and with decreased activity in bilateral prefrontal and parietal cortices, consistent with reduced response conflict (32). A similar study confirmed involvement of the prefrontal brain regions in maintaining attentional control over conflicting response systems during the ST (33). With regard to the DST, a functional MRI study in young healthy volunteers (mean age 22 years) showed recruitment of the fronto-parietal cortical network during the execution of the test (34). This network included the bilateral inferior frontal cortices, left frontal eye field and left posterior parietal cortex (34). In older adults (mean age 81 years), DST performance was associated with peak functional MRI activation from executive control function regions, including the left middle frontal gyrus and right posterior parietal cortex (35).

In spite of the abundant literature on the association between neurocognitive performance and exposure to lead in older adults, the underlying molecular mechanisms remain largely hypothetical. Pathways that might be involved include neural apoptosis (36), inflammation 
and oxidative stress $(37,38)$, mitochondrial damage (39) and disturbances of neurotransmitter storage and release, such as dopamine (40). In animal studies, lead distribution in brain was found in the frontal cortex (consistent with the MRI studies in humans), thalamus, hippocampus, cerebellum, olfactory bulb and other brain regions. In most $(41,42)$, albeit not all $(43)$ rat studies, the hippocampus was the brain region with the highest lead concentration. In one study of four brains of adult men (age range 36-43 years) without occupational exposure to lead, the highest lead levels were also found in the hippocampus and the amygdala (44).

\section{Strengths and limitations}

What our study adds to the literature is its focus on young male workers recruited from 2015 onwards, partially reflecting current environmental exposure in the US prior to chronic occupational exposure. Furthermore, we ran sensitivity analyses based on age stratification to minimize bias related to the cumulative lead dose. Nevertheless, our current findings must also be interpreted within the context of their limitations. First, our sample size was of the same order of magnitude as in many previous studies on neurocognitive function (12). However, in post-hoc calculations, the power to detect an association with blood lead was only 0.18 for the mean reaction time in incongruent trials of the ST and 0.46 for mean total latency in the DST. Second, findings in workers cannot be extrapolated to the general population because of the so-called healthy worker effect (45) Third, the cross-sectional nature of our current analysis is vulnerable to bias, for instance in measurements that change over a person's life course and does also not allow to make any causal inference. Fourth, although our study population was ethnically diverse, it included few Asians and no women. Fifth, in contrast to other studies, in which a comprehensive array of neurocognitive function tests were administered $(1,3-5,7)$, in view of the time workers could devote to being studied in an occupational setting, we only administered two tests. Finally, a potential limitation of our study was that we did not measure bone lead as exposure marker. Approximately $95 \%$ of the total body burden of lead is present in the skeleton, and measurement of bone lead levels can provide a more accurate measure of the internal dose (46). However, blood lead reflects both recent exogenous exposure and endogenous redistribution of the lead stored in bone (46). Moreover, in the longitudinal NHS, there was little evidence among 68-year old women supporting an association between cognitive decline and bone lead (7).

\section{Concluding remarks}

At the exposure levels in our current study, we failed

to demonstrate a significant association of blood lead with neurocognitive performance in a cross-sectional analysis of young American men. The workers enrolled in SPHERL are being followed up for two years, during which time they will be chronically exposed to lead and their blood lead concentration is expected to increase 3- to 5-fold. This longitudinal follow-up will potentially generate new data relating neurocognitive function to lead exposure, which might inform occupational standards.

\section{Funding}

The European Union (HEALTH-F7-305507 HOMAGE) and the European Research Council (Advanced Researcher Grant 2011-294713-EPLORE and Proofof-Concept Grant 713601-uPROPHET), the European Research Area Net for Cardiovascular Diseases (JTC2017-046-PROACT), and the Fonds voor Wetenschappelijk Onderzoek Vlaanderen, Ministry of the Flemish Community, Brussels, Belgium (G.0881.13) currently support the Research Unit Hypertension and Cardiovascular Research. The sponsors had no role in the preparation of this report

\section{Declaration of interest}

In support of SPHERL, the Research Unit Hypertension and Cardiovascular Epidemiology received an unrestricted grant from the International Lead Association (www.ila-lead.org).

\section{Acknowledgements}

The authors gratefully acknowledge the nursing staff employed at the study sites in the US and the expert clerical assistance of Vera De Leebeeck and Renilde Wolfs at the Studies Coordinating Centre in Leuven, Belgium.

\section{References}

1. Payton M, Riggs KM, Spiro A 3rd, Weiss ST, Hu H. Relations of bone and blood lead to cognitive function: the VA Normative Aging Study. Neurotoxicol Teratol 1998 Jan-Feb;20(1):19-27. https://doi.org/10.1016/S08920362(97)00075-5.

2. Wright RO, Tsaih SW, Schwartz J, Spiro A 3rd, McDonald $\mathrm{K}$, Weiss ST et al. Lead exposure biomarkers and minimental status exam scores in older men. Epidemiology 2003 Nov;14(6):713-8. https://doi.org/10.1097/01. EDE.0000081988.85964.db. 
3. Shih RA, Glass TA, Bandeen-Roche K, Carlson MC, Bolla KI, Todd AC et al. Environmental lead exposure and cognitive function in community-dwelling older adults. Neurology 2006 Nov;67(9):1556-62. https://doi. org/10.1212/01.wnl.0000239836.26142.c5.

4. Weisskopf MG, Proctor SP, Wright RO, Schwartz J, Spiro A 3rd, Sparrow D et al. Cumulative lead exposure and cognitive performance among elderly men. Epidemiology 2007 Jan;18(1):59-66. https://doi.org/10.1097/01. ede.0000248237.35363.29.

5. Weuve J, Korrick SA, Weisskopf MG, Ryan LM, Schwartz $\mathrm{J}$, Nie $\mathrm{H}$ et al. Cumulative exposure to lead in relation to cognitive function in older women. Environ Health Perspect 2009 Apr;117(4):574-80. https://doi.org/10.1289/ ehp.11846.

6. van Wijngaarden E, Winters PC, Cory-Slechta DA. Blood lead levels in relation to cognitive function in older U.S. adults. Neurotoxicology 2011 Jan;32(1):110-5. https://doi. org/10.1016/j.neuro.2010.11.002.

7. Power MC, Korrick S, Tchetgen Tchetgen EJ, Nie LH, Grodstein $\mathrm{F}, \mathrm{Hu} \mathrm{H}$ et al. Lead exposure and rate of change in cognitive function in older women. Environ Res 2014 Feb;129:69-75. https://doi.org/10.1016/j. envres.2013.12.010.

8. Schwartz BS, Lee BK, Lee GS, Stewart WF, Lee SS, Hwang $\mathrm{KY}$ et al. Associations of blood lead, dimercaptosuccinic acid-chelatable lead, and tibia lead with neurobehavioral test scores in South Korean lead workers. Am J Epidemiol 2001 Mar;153(5):453-64. https://doi.org/10.1093/aje/153.5.453.

9. Barth A, Schaffer AW, Osterode W, Winker R, Konnaris C, Valic E et al. Reduced cognitive abilities in lead-exposed men. Int Arch Occup Environ Health 2002 Aug; 75(6):394-8. https://doi.org/10.1007/s00420-002-0329-1.

10. Schwartz BS, Lee BK, Bandeen-Roche K, Stewart W, Bolla $\mathrm{K}$, Links J et al. Occupational lead exposure and longitudinal decline in neurobehavioral test scores. Epidemiology 2005 Jan;16(1):106-13. https://doi.org/10.1097/01. ede.0000147109.62324.51.

11. Winker R, Barth A, Ponocny-Seliger E, Pilger A, Osterode W, Rüdiger HW. No cognitive deficits in men formerly exposed to lead. Wien Klin Wochenschr 2005 Nov;117(2122):755-60. https://doi.org/10.1007/s00508-005-0466-0.

12. Shih RA, Hu H, Weisskopf MG, Schwartz BS. Cumulative lead dose and cognitive function in adults: a review of studies that measured both blood lead and bone lead. Environ Health Perspect 2007 Mar;115(3):483-92. https:// doi.org/10.1289/ehp.9786.

13. Rabinowitz MB. Toxicokinetics of bone lead. Environ Health Perspect 1991 Feb;91:33-7. https://doi.org/10.1289/ ehp.919133.

14. Gartside PS. The relationship of blood lead levels and blood pressure in NHANES II: additional calculations. Environ Health Perspect 1988 Jun;78:31-4. https://doi.org/10.1289/ ehp. 887831 .

15. Pirkle JL, Brody DJ, Gunter EW, Kramer RA, Paschal
DC, Flegal KM et al.; The National Health and Nutrition Examination Surveys (NHANES). The decline in blood lead levels in the United States. JAMA 1994 Jul;272(4):284-91. https://doi.org/10.1001/jama.1994.03520040046039.

16. Muntner P, He J, Vupputuri S, Coresh J, Batuman V. Blood lead and chronic kidney disease in the general United States population: results from NHANES III. Kidney Int 2003 Mar;63(3):1044-50. https://doi.org/10.1046/j.15231755.2003.00812.x.

17. Bleecker ML, Lindgren KN, Ford DP. Differential contribution of current and cumulative indices of lead dose to neuropsychological performance by age. Neurology 1997 Mar;48(3):639-45. https://doi.org/10.1212/WNL.48.3.639.

18. Hara A, Gu YM, Petit T, Liu YP, Jacobs L, Zhang ZY et al. Study for promotion of health in recycling lead-rationale and design. Blood Press 2015 Jun;24(3):147-57. https://doi. org/10.3109/08037051.2014.996409.

19. General Assembly of the World Medical Association. World Medical Association Declaration of Helsinki: ethical principles for medical research involving human subjects. J Am Coll Dent 2014;81(3):14-8.

20. Lauwerys R, Amery A, Bernard A, Bruaux P, Buchet JP, Claeys $\mathrm{F}$ et al. Health effects of environmental exposure to cadmium: objectives, design and organization of the Cadmibel Study: a cross-sectional morbidity study carried out in Belgium from 1985 to 1989. Environ Health Perspect 1990 Jul;87:283-9. https://doi.org/10.1289/ehp.9087283.

21. Schutte R, Nawrot TS, Richart T, Thijs L, Vanderschueren $\mathrm{D}$, Kuznetsova $\mathrm{T}$ et al. Bone resorption and environmental exposure to cadmium in women: a population study. Environ Health Perspect 2008 Jun;116(6):777-83. https:// doi.org/10.1289/ehp.11167.

22. Centers for Disease Control and Prevention. Screening young children for lead poisoning: Guidance for state and local public health officials; Appendix C3: Proficiency Testing and Quality Control. Available from: www.cdc.gov/nceh/lead/ publications/screening.htm. Accessed December 18, 2018.

23. Centers for Disease Control and Prevention. Screening young children for lead poisoning: Guidance for state and local public health officials; Appendix C1: The Lead Laboratory. Available from: www.cdc.gov/nceh/lead/publications/ screening.htm. Accessed December 18, 2018.

24. Westgard JO, Barry PL, Hunt MR, Groth T. A multi-rule Shewhart chart for quality control in clinical chemistry. Clin Chem 1981 Mar;27(3):493-501.

25. Centers for Disease Control and Prevention. CLIA ' 88 Focus on Clinic and Office Laborarories. Available from: wonder.cdc.gov/wonder/prevguid/p0000090/p0000090.asp. Accessed December 18, 2018.

26. Bland JM, Altman DG. Statistical methods for assessing agreement between two methods of clinical measurement. Lancet 1986 Feb;1(8476):307-10. https://doi.org/10.1016/ S0140-6736(86)90837-8.

27. White RF, James KE, Vasterling JJ, Letz R, Marans $\mathrm{K}$, Delaney $\mathrm{R}$ et al. Neuropsychological screening 
for cognitive impairment using computer-assisted tasks. Assessment 2003 Mar;10(1):86-101. https://doi. org/10.1177/1073191102250185.

28. Proust-Lima C, Amieva H, Dartigues JF, Jacqmin-Gadda H. Sensitivity of four psychometric tests to measure cognitive changes in brain aging-population-based studies. Am J Epidemiol 2007 Feb;165(3):344-50. https://doi. org/10.1093/aje/kwk017.

29. Rosano C, Perera S, Inzitari M, Newman AB, Longstreth WT, Studenski S. Digit Symbol Substitution test and future clinical and subclinical disorders of cognition, mobility and mood in older adults. Age Ageing 2016 Sep;45(5):688-95. https://doi.org/10.1093/ageing/afw116.

30. Krieg EF Jr, Chrislip DW, Crespo CJ, Brightwell WS, Ehrenberg RL, Otto DA. The relationship between blood lead levels and neurobehavioral test performance in NHANES III and related occupational studies. Public Health Rep 2005 May-Jun;120(3):240-51. https://doi. org/10.1177/003335490512000305.

31. Krieg EF Jr, Butler MA. Blood lead, serum homocysteine, and neurobehavioral test performance in the third National Health and Nutrition Examination Survey. Neurotoxicology 2009 Mar;30(2):281-9. https://doi. org/10.1016/j.neuro.2008.12.014.

32. Egner T, Hirsch J. The neural correlates and functional integration of cognitive control in a Stroop task. Neuroimage 2005 Jan;24(2):539-47. https://doi.org/10.1016/j. neuroimage.2004.09.007.

33. Harrison BJ, Shaw M, Yücel M, Purcell R, Brewer WJ, Strother SC et al. Functional connectivity during Stroop task performance. Neuroimage 2005 Jan;24(1):181-91. https:// doi.org/10.1016/j.neuroimage.2004.08.033.

34. Usui N, Haji T, Maruyama M, Katsuyama N, Uchida S, Hozawa A et al. Cortical areas related to performance of WAIS Digit Symbol Test: a functional imaging study. Neurosci Lett 2009 Sep;463(1):1-5. https://doi. org/10.1016/j.neulet.2009.07.048.

35. Venkatraman VK, Aizenstein H, Guralnik J, Newman AB, Glynn NW, Taylor C et al. Executive control function, brain activation and white matter hyperintensities in older adults. Neuroimage 2010 Feb;49(4):3436-42. https://doi. org/10.1016/j.neuroimage.2009.11.019.

36. Engstrom A, Wang H, Xia Z. Lead decreases cell survival, proliferation, and neuronal differentiation of primary cultured adult neural precursor cells through activation of the JNK and p38 MAP kinases. Toxicol In Vitro 2015 Aug;29(5):1146-55. https://doi.org/10.1016/j. tiv.2015.05.001
37. Wei J, Du K, Cai Q, Ma L, Jiao Z, Tan J et al. Lead induces COX-2 expression in glial cells in a NFAT-dependent, AP-1/ NFKB-independent manner. Toxicology 2014 Nov;325:6773. https://doi.org/10.1016/j.tox.2014.08.012.

38. Baranowska-Bosiacka I, Gutowska I, Marchlewicz M, Marchetti C, Kurzawski M, Dziedziejko V et al. Disrupted pro- and antioxidative balance as a mechanism of neurotoxicity induced by perinatal exposure to lead. Brain Res 2012 Jan;1435:56-71. https://doi.org/10.1016/j. brainres.2011.11.062.

39. Sousa CA, Soares EV. Mitochondria are the main source and one of the targets of $\mathrm{Pb}$ (lead)-induced oxidative stress in the yeast Saccharomyces cerevisiae. Appl Microbiol Biotechnol 2014 Jun;98(11):5153-60. https://doi.org/10.1007/s00253014-5631-9.

40. Verstraeten SV, Aimo L, Oteiza PI. Aluminium and lead: molecular mechanisms of brain toxicity. Arch Toxicol 2008 Nov;82(11):789-802. https://doi.org/10.1007/s00204-0080345-3.

41. Wang Q, Luo W, Zheng W, Liu Y, Xu H, Zheng G et al. Iron supplement prevents lead-induced disruption of the blood-brain barrier during rat development. Toxicol Appl Pharmacol 2007 Feb;219(1):33-41. https://doi. org/10.1016/j.taap.2006.11.035.

42. Kishi R, Ikeda T, Miyake H, Uchino E, Tsuzuki T, Inoue K. Regional distribution of lead, zinc, iron and copper in suckling and adult rat brains. Brain Res 1982 Nov;251(1):180-2. https://doi.org/10.1016/00068993(82)91289-6.

43. Widzowski DV, Cory-Slechta DA. Homogeneity of regional brain lead concentrations. Neurotoxicology 1994;15(2):295-307.

44. Grandjean P. Regional distribution of lead in human brains. Toxicol Lett 1978;2:65-9. https://doi.org/10.1016/03784274(78)90065-6.

45. Nuyts GD, Elseviers MM, De Broe ME. Healthy worker effect in a cross-sectional study of lead workers. J Occup Med 1993 Apr;35(4):387-91.

46. $\mathrm{Hu}$ H, Shih R, Rothenberg S, Schwartz BS. The epidemiology of lead toxicity in adults: measuring dose and consideration of other methodologic issues. Environ Health Perspect 2007 Mar;115(3):455-62. https://doi.org/10.1289/ ehp.9783.

Received for publication: 19 September 2018 